\section{N BRIEF}

- Crown provision has seen an enormous increase over the past three decades. In the UK around 1 million teeth are fitted with crowns every year, many of these requiring complex additional treatment prior to crown placement

- Around $15 \%$ of NHS dental spending annually is on crown provision and maintenance, so the total cost is very large

- The pressures on dentists to produce high quality restorations is probably increasing and will not diminish

- There are few data on the quality or longevity of restorations placed

- Technological advances have changed the way we are able to practice over recent decades, and further developments will open up new possibilities

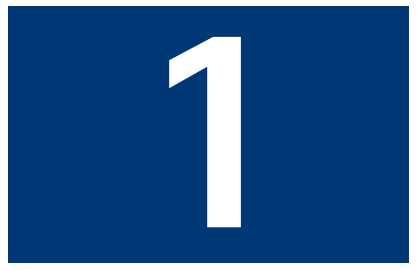

\title{
Changing patterns and the need for quality
}

\author{
J. G. Steele ${ }^{1}$ R. W. Wassell ${ }^{2}$ and A. W. G. Walls ${ }^{3}$
}

This series of articles is aimed at anybody who places crowns and other extra-coronal restorations (ie veneers and shims) on individual teeth. We hope that everyone from experienced practitioners to undergraduate students may find something of value. Whoever reads them, we would ask to do so with an open mind. We have tried not to be dogmatic, and the techniques and materials described are not the only ones available, but are the ones which accord with the principles we describe.

CROWNS AND EXTRA-CORONAL RESTORATIONS:

\section{Changing patterns and} the need for quality

2. Materials considerations

3. Pre-operative assessment

4. Endodontic considerations

5. Jaw registration and articulator selection

6. Aesthetic control

7. Cores for teeth with vital pulps

8. Preparations for full veneer crowns

9. Provisional restorations

10. Impression materials and technique

11. Try-in and cementation of crowns

12. Porcelain veneers

13. Resin bonded metal restorations

1"Senior Lecturer in Restorative Dentistry, 2 Senior Lecturer in Restorative Dentistry, ${ }^{3}$ Professor of Restorative Dentistry, Department of Restorative Dentistry, The Dental School, Framlington Place, Newcastle upon Tyne NE2 4BW ${ }^{*}$ Correspondence to: J. G. Steele E-mail:jimmy.steele@ncl.ac.uk

\section{Refereed Paper}

( British Dental Journal 2002; 192:

144-148
Our aim in these articles is, by working from a sound theoretical base, to try to give the reader the background to pick the best treatment options from the wide, and continuously changing, range available. Technical issues are important and will be addressed, but there is a need to recognise that the provision of extra-coronal restorations is more than just cutting a shape which is free of undercuts, on to which something can be cemented. Cutting a preparation and cementing a restoration are relatively easy. Cutting a preparation and cementing a restoration which will last for many years without any further damage to the dental tissues is a different matter. Treatment planning issues and materials choices will occupy a greater part of this series of articles than the technicalities of tooth preparation.

We have concentrated on single tooth restorations, but all of the principles described also apply to more complex multiple restorations, including fixed bridges. However, we have not specifically covered replacement of missing teeth with bridges or implants. Replacement of teeth involves consideration of a range of additional issues and treatment planning decisions, whilst an entirely different set of technical rules are required for the consideration of implants. These will be left for future authors to address.

In an ideal world we would have been able to draw on the conclusions of full systematic reviews of the literature, based on randomised controlled clinical trials. Such an approach is widely used in many areas of medicine and allows objective assessment of the available techniques, drugs or materials. Few such reviews are available in this area of dentistry though, probably because the raw material from which they are derived, namely randomised controlled clinical trials, are themselves so sparse. Where possible, we have tried to support what we write with appropriate previously published scientific evidence, but good quality evidence is scarce and much of what has been written in the past is based on the experience of clinicians, or on theoretical considerations. This does not necessarily devalue existing practices, but it does make it more difficult to make objective choices about treatment planning, materials or techniques. We have tried to identify where there is and where
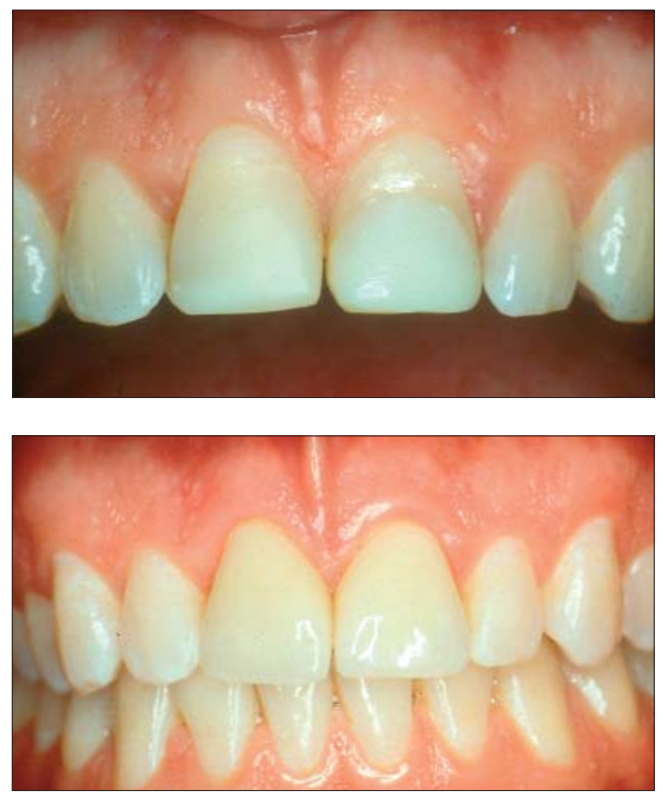

Fig. $1 \mathrm{a}$ and $1 \mathrm{~b}$. The provision of good quality crowns or alternative adhesive restorations can result in a tremendous improvement in oral health for the patient as well as being a fulfilling experience for the dentist. Despite being a relatively minor procedure, this patient's aesthetics and confidence were improved enormously by the provision of these anterior dentine bonded crowns 
Fig. 2 A series of radiographs taken over a five year period showing how the provision of crowns can be detrimental to oral health where the treatment is ill thought out and, in this case, poorly executed. This is a graphic illustration of 'the need for quality'

Fig. 2a Initial presentation revealed crowns on lower anterior teeth with early root caries on several teeth

Fig. 2b Treatment is planned and started but the caries has progressed and periapical pathology quickly becomes apparent. Root treatment is started on affected teeth, without dealing with the root caries and its causes

Fig. 2c Root treatment continues apace but with little attention to coronal seal
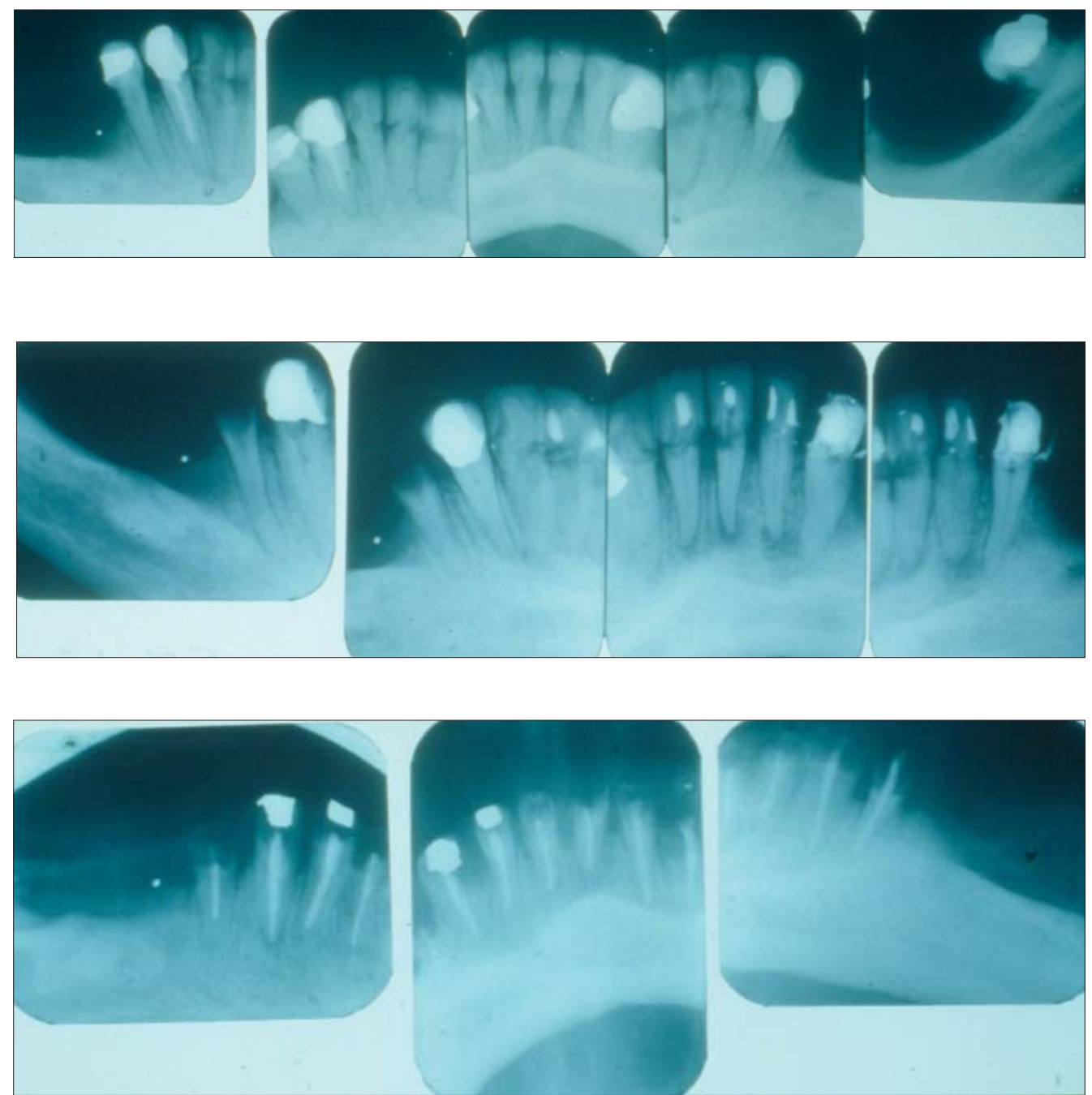

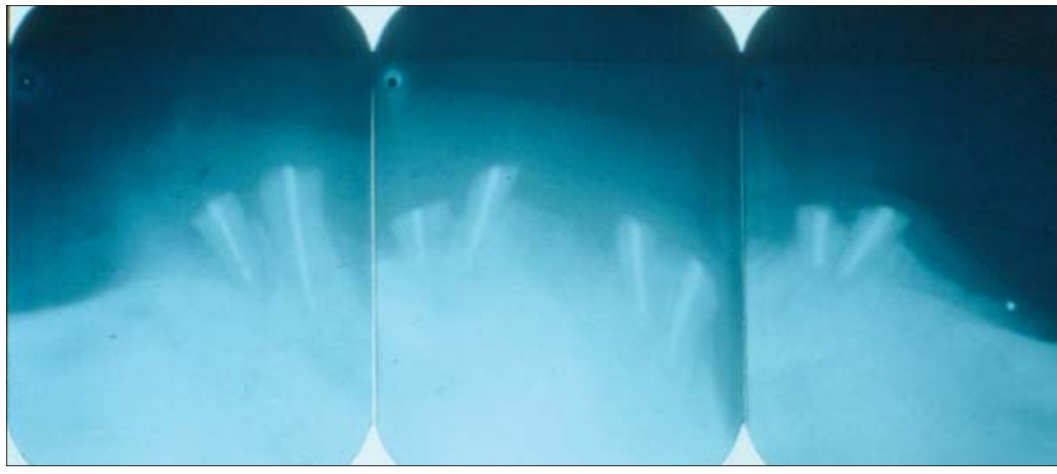

Fig. $2 \mathrm{~d}$ A decision is made to progress to overdentures

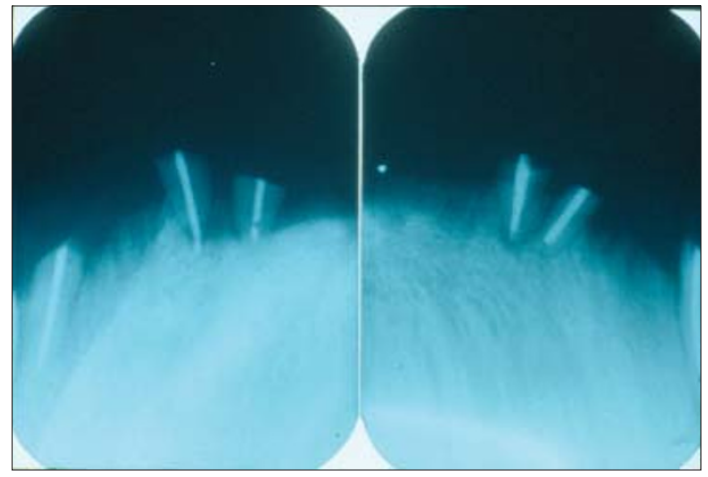

Fig. 2e Periodontal attachment loss and periapical pathology render overdenture abutments useless

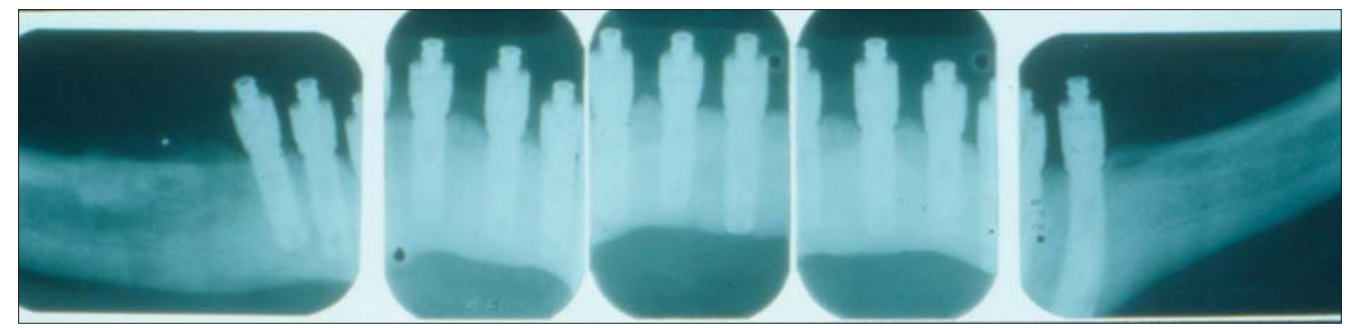




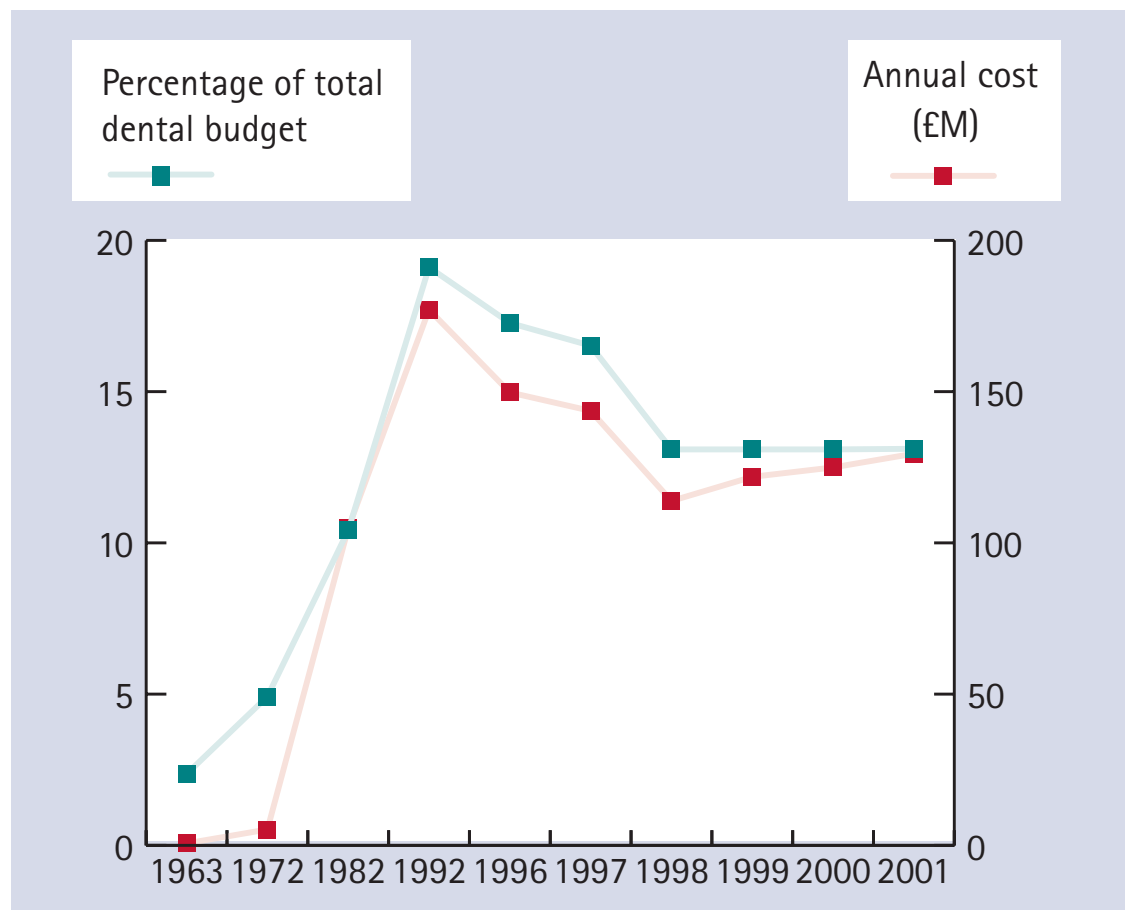

Fig. 3 The cost of overall crown provision under the National Health Service for adults aged over 18 years, 1963 to $1995 / 96$ (figures for cost not taking into account annual inflation) (Note: The scale on the $\mathrm{x}$-axis is non-linear)

\section{Number recemented (thousands)}

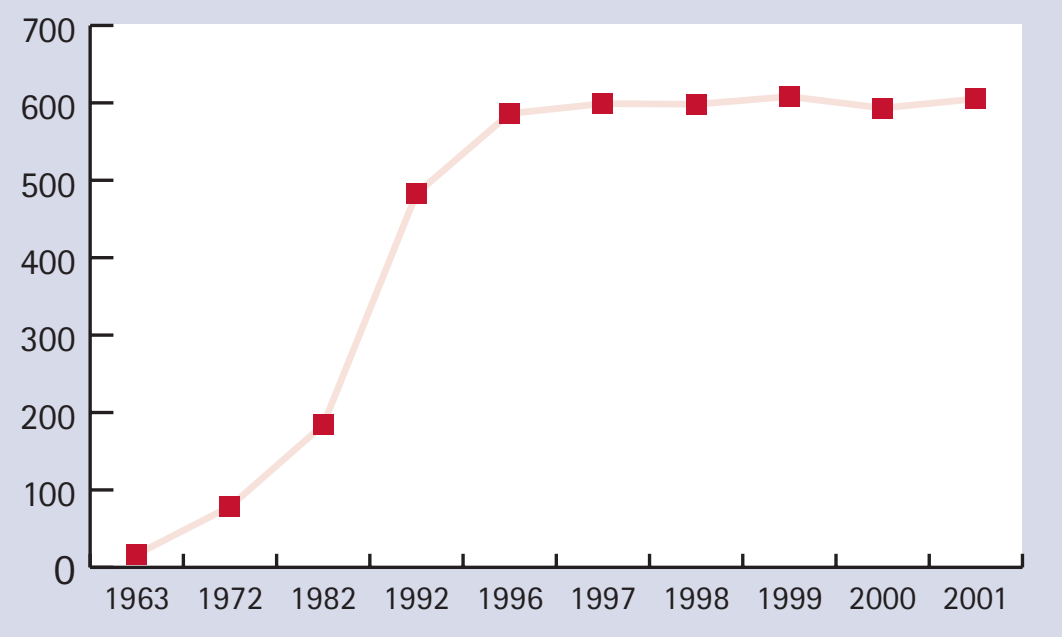

Fig. 4 The total number of crowns (in thousands) recemented under the National Health Service for adults aged over 18 years, 1963-1995/96 (Note: The scale on the x-axis is non-linear)

there is not strong evidence to support what we write, but inevitably we have often had to write from experience or theory.

The series consists of 13 individual articles, each of which should be able to stand alone. For each of these we will set, at the start of the paper, the specific learning objectives which we hope to meet. In a series like this it is impossible to explore every technique or material ever described, this would make for very heavy reading and very dull writing. We hope though that these articles should enable the reader to evaluate his or her own practices against a set of fundamental principles.
The rest of this article will present some background data which illustrate the health benefits, the health problems, the scale and the cost of crown provision, and the potential for technological change to help us to improve oral health.

\section{BACKGROUND: THE NEED FOR QUALITY}

\section{Crowns and oral health}

As we progress in the new millennium, a rich blend of improving technology, better oral health, a strengthening scientific base and the timeless ability to employ fine manual skills and artistry are making it increasingly possible, and enjoyable, for the dentist to deliver good quality restorations. Moreover, it is also increasingly possible to do this with the minimum of damage to the dental tissues.

The health benefits of providing high quality restorations are essential, substantial and long lasting. Current concepts of health include positive aspects of quality of life; self esteem and the ability to undertake daily activities, such as eating, speaking and socialising, comfortably and without embarrassment. It is here that restorative dental care has a major impact on health. Even in a simple case, such as that in Figure 1a, where an incisal tip has fractured and the composite repair is functional but dull, lifeless and unsightly in the eyes of the patient, the pretreatment restoration can be a cause of embarrassment. Well executed restorations could (and did, see Fig. 1b) make a substantial positive impact on this individual's well being. In a dentition extensively broken down by years of disease and wear the functional and aesthetic disability can be much greater and the benefit more dramatic. It is true that poorly executed treatment may have the opposite effect. Figure 2 shows a series of radiographs of a patient where crowns have been poorly conceived, ill-planned and carelessly executed. The case is as graphic an illustration of the need for both good planning and skilful execution as it is possible to find, and we will be using this case to illustrate a number of specific points in a later article.

\section{Historical trends}

The number of crowns placed by dentists in Europe and North America is vast and in many countries the volume has been increasing year on year. In England and Wales, where data are available from the National Health Service (NHS), the number of treatments showed a rapid increase over the past 30-40 years with the cost peaking at nearly £180M in 1991/1992 (Fig. 3). ${ }^{1-5}$ It reduced significantly in the early 1990s when some dentists moved out of NHS practice following contractual changes, and then very markedly in 1997 when porcelain fused to metal restorations on molar teeth were removed from the list of permitted items. Despite the reduction, the sums spent are still vast: around $£ 142 \mathrm{M}$ in 2000-2001 for crowns alone, but Ł6M for veneers, $€ 11.5 \mathrm{M}$ for large onlays (having undergone a very sharp rise since 1997) and £33.5M 
for bridges. Around a third of the dentate adult population have at least one artificial crown, and amongst adults now in their 50s and 60s, half have a crown. Those with crowns have around three per head on average. ${ }^{6}$ These figures are derived from the 1998 UK Adult Dental Health Survey and show a marked increase from the situation a decade earlier. Data from other countries are less easily available, but what data there are suggest that trends in Western Europe and North America are broadly similar.

The dental and demographic trends in the population will ensure that the need for full coverage and other extra-coronal restorations will not diminish in the foreseeable future. In addition to the need to maintain and replace existing crowns, there is a tidal wave of heavily restored teeth in the middle-aged group in many western countries which resulted from treatment of higher levels of caries in the 1950s, 60s and 70s. ${ }^{6}$ These heavily restored teeth are now getting old. As the restorations in them age they will need to be replaced, and as they are replaced they will get larger. The number of cases where there has been extensive loss of tooth tissue, and therefore where full coverage restorations may be indicated, looks unlikely to diminish. It may even increase. Furthermore, the need for such restorations will tend to be concentrated towards the older end of the age spectrum, providing an additional challenge for the clinician. At the same time increasingly litiginous consumers will demand high quality restorations, and may be prepared to recover their costs through the courts if their treatment is ill-conceived or poorly executed. The pressures on practising dentists to produce high quality restorative dentistry has never been higher, and will not reduce.

\section{Quality issues}

Despite the vast number of crowns placed and the need for high quality, we know very little indeed about the performance of these restorations. Even simple data on the longevity of crowns, and the rate of loss or replacement are limited. Research findings are often difficult to interpret because of variability in the selection criteria and treatment techniques used. Certainly, the number of crowns which are dislodged and require to be recemented is large in the UK; well over half a million crowns are recemented every year under the NHS. This figure rose rapidly in the 1980s and 90s reflecting the increase in overall crown provision(Fig. 4). ${ }^{1-5}$ But, crowns which fall out are only one manifestation of failure. Others include those which become carious, periodontally compromised or in which the pulps become inflamed or necrotic as a result of the treatment provided. Evidence for the longterm effects of crown preparation on vital teeth is very sparse indeed. There are estimates of the damage to pulp vitality which occurs following tooth reduction for crowns and bridges. This indicates that anything from 1-15\% of teeth lose vitality after preparation, with two of the three studies cited here approaching the higher end of

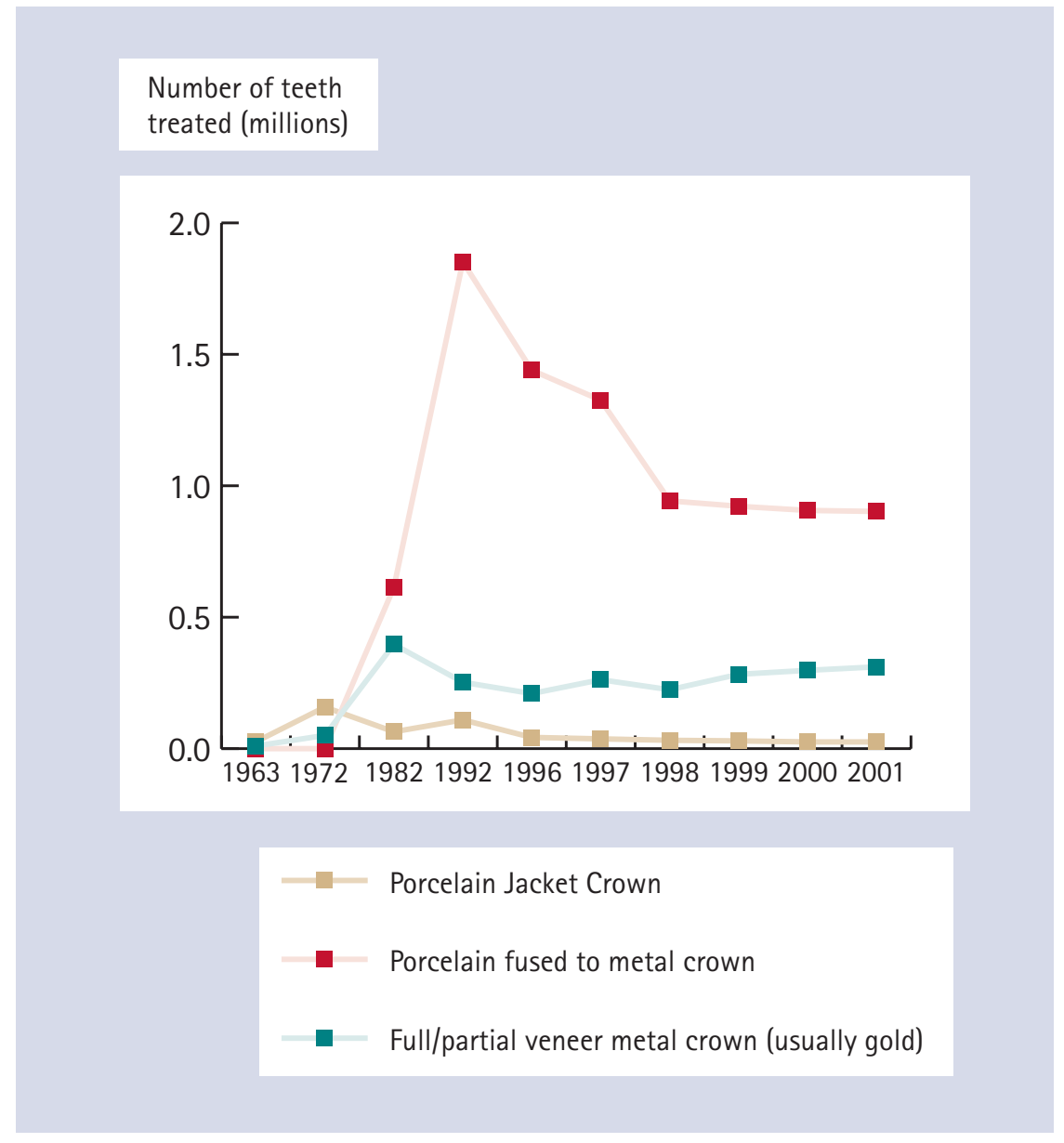

Fig. 5 The total number of crowns of different types (all metal, porcelain fused to metal and all porcelain) provided under the National Health Service for adults aged over 18 years, 1963-1995/96 (Note: The scale on the $x$-axis is non-linear)
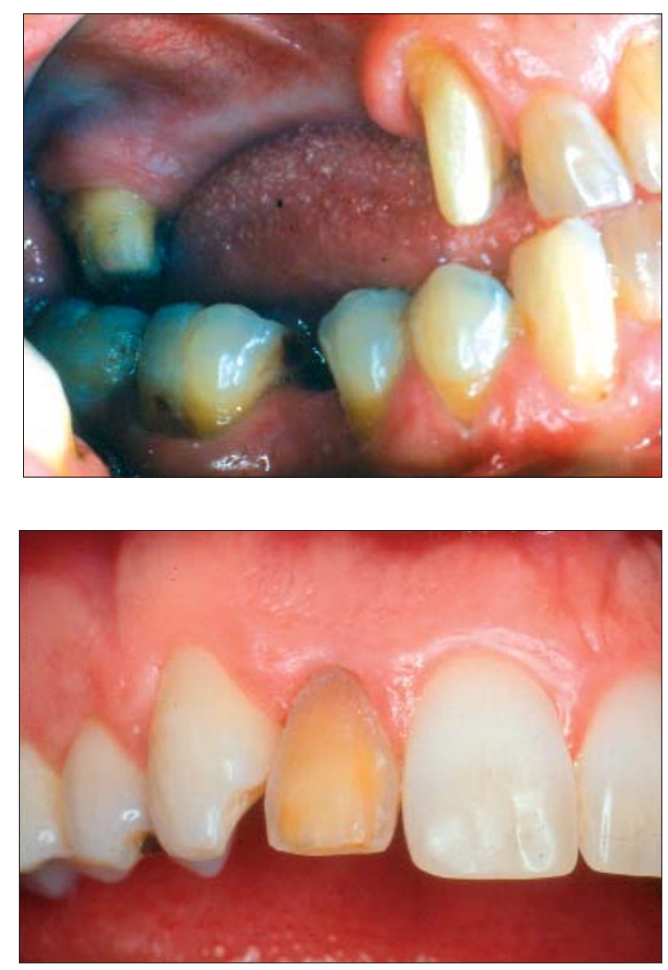

Fig. 6a and $6 \mathrm{~b}$ Adhesive dentistry has much to commend it. Contrast the destructive preparation for conventional porcelain fused to metal restoration (4a) with the much more conservative preparation for a porcelain veneer (4b) 


\section{PRACTICE}
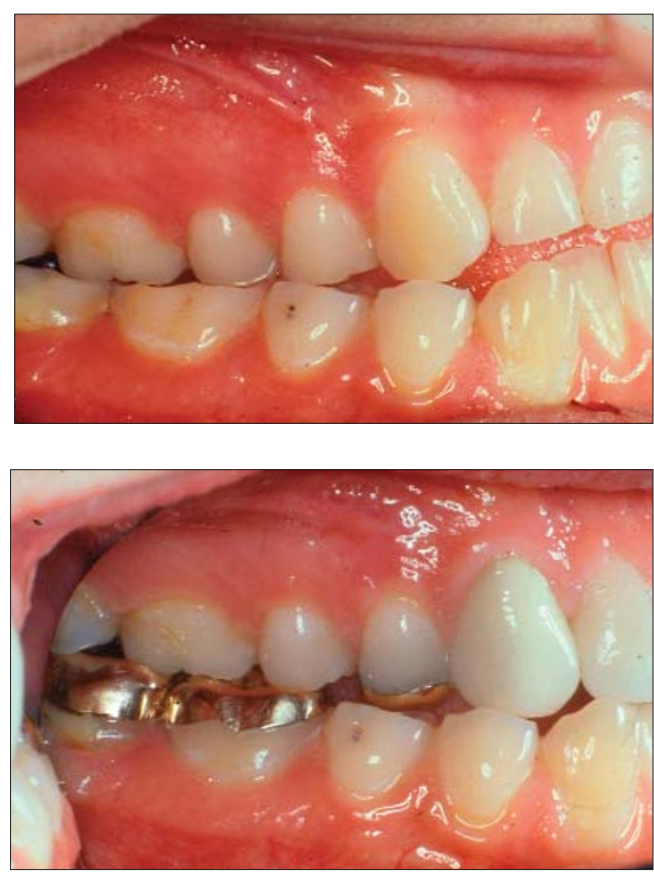

Fig. 7a and 7b With the spectrum of restorations now available, some cases are best treated with a combination of conventional and adhesive approaches

the range. ${ }^{7-9}$ For various reasons these estimates may not be representative of typical adult populations, but they do indicate that irreversible pulp damage is likely to be a substantial problem. There are very few useful quantitative data on other forms of failure. In these articles we have tried to use the limited evidence available to identify and then to address the reasons for failure.

\section{Technological solutions}

Technological advances over the past 30 years have offered many potential solutions to some of these problems, and have in turn played their part in changing treatment patterns as well. The traditional boundaries between routine and advanced restorative work have become blurred as new techniques and materials have proliferated, so much so that we found it difficult to decide on a title for this series of articles. All metal and all porcelain restorations have largely given way to porcelain fused to metal restorations (Fig. 5 shows data for the UK National Health Service), ${ }^{1-5}$ but changes in porcelain technology are starting to provide improved all-porcelain alternatives again, though it may be some time before their use becomes widespread. Looking beyond this, it is possible to envisage a greater place for composite resins as an alternative to porcelains in future years. However, it is the rapid development of adhesive technology, particularly where bonding to dentine is concerned, that has provided the greatest potential for change and the most exciting possibilities. Above all, preparations can be made much less destructive and are often quicker to cut (Figs 6a and 6b). For all their attractions though, adhesive restorations create their own problems. Provisional restorations are difficult to make, and the final restoration is often awkward to adjust and to cement. They are highly technique sensitive, requiring additional skills and care if they are to be successful.

In this series we will attempt to outline a set of principles for the provision both of conventional and adhesive restorations (Figs 7a and 7b) with the aim of improving oral health.
1 Dental Practice Board. Digest of Statistics 1995-2001. Part 1Detailed analysis of GDS treatment outcomes. DPB, Eastbourne. Data for 1996-2001 available at: http://www.bdta-dentistry.org.uk/ dentaldata/index.html

2 Dental Practice Board. Digest of Statistics 1991-92. Part 1-Detailed analysis of GDS treatment outcomes. DPB, Eastbourne.

3 Dental Estimates Board. Statistics 1963. DEB, Eastbourne.

4 Dental Estimates Board. Annual Report 1972. DEB, Eastbourne.

5 Dental Estimates Board. Annual Report 1982. DEB, Eastbourne.

6 Kelly M, Steele J, Nuttall N, Bradnock G, Morris J, Nunn J, Pine C, Pitts N, Treasure E, White D. Adult Dental Health Survey: Oral Health in the United Kingdom in 1998. (2000) London: TSO.

7 Felton D, Madison S, Kanoy E, Kantor $M$, Maryniuk $G$. Long term effects of crown preparation on pulp vitality. $J$ Dent Res 1989; 68 (special issue):1009. Abstract 1139.

8 Bergenholtz G, Nyman S. Endodontic complications following periodontal and prosthetic treatment of patients with advanced periodontal disease. J Periodontol 1984; 55: 63-68.

9 Reuter J E, Brose M 0. Failures in full crown retained dental bridges. Br Dent J 1984; 157: 61-63. 